\title{
Utilização de parte da região codificadora da glicoproteína b na diferenciação do herpesvírus bovino 1.1, herpesvírus bovino 1.2 e herpesvírus bovino 5
}

\author{
[Utilization of part of the region which codes for glycoprotein b in bovine herpesvirus 1.1, \\ bovine herpesvirus 1.2 and bovine herpesvirus 5] \\ E.A. Costa ${ }^{1}$, E.F. Barbosa-Stancioli ${ }^{2}$, R.C. Leite $^{1}$, G.D.R. Oliveira ${ }^{1}$, M.A. Rocha ${ }^{1 *}$ \\ ${ }^{1}$ Escola de Veterinária da Universidade Federal de Minas Gerais \\ Caixa Postal 567 \\ 30123-970 - Belo Horizonte, MG \\ ${ }^{2}$ Instituto de Ciências Biológicas - UFMG - Belo Horizonte, MG
}

\begin{abstract}
RESUMO
Utilizou-se uma reação em cadeia de polimerase (PCR) previamente desenvolvida para a amplificação de parte da região única longa 27 (UL27) do genoma de herpesvírus bovino 1.1 (BoHV-1), que codifica a glicoproteína B, buscando a diferenciação entre isolados de BoHV-1.1 e BoHV-5. Os produtos de PCR gerados a partir de isolados de BoHV-1.1 e BoHV-5 mostraram padrão de amplificação diferenciado em seus tamanhos moleculares. Analisando as seqüências de nucleotídeos dos produtos de PCR obtidos de dois isolados de BoHV-5, juntamente com as seqüências dos produtos de PCR obtidos de um isolado de BoHV-1.1 e de três isolados de BoHV-1.2, previamente depositados no GenBank, verificou-se que a diferença observada na amplificação se deve ao número de repetições de G-C presentes no final da região codificadora da gB, particularmente nas seqüências 5'-G(A/T)CC-3'. A análise dessas seqüênciasmotivo desponta como uma ferramenta auxiliar na diferenciação entre isolados de BoHV-1.1, BoHV-1.2 e BoHV-5.
\end{abstract}

Palavras-chave: BoHV-1.1, BoHV-1.2, BoHV-5, gB, PCR, seqüências-motivo

\begin{abstract}
A previously-developed PCR was used for the amplification of part of the UL27 region of the BoHV-1.1 genome, which codes for glycoprotein B, seeking the differentiation between BoHV-1.1 and BoHV-5 isolates. The PCR products generated from the BoHV-1 and BoHV-5 isolates showed a pattern of differentiated amplification of their molecular size. The PCR of the BoHV-5 products were sequenced and the results compared with the sequence of the BoHV-1.1 and BoHV-1.2 isolates previously deposited in the GenBank. It was verified that the difference between the PCR products is due to greater number of repetitions of $G-C$ present at the end of the $g B$ codifier region. The most common repeat sequences were 5 '-G(A/T)CC-3'. The analysis of these repetitions was shown to be an auxiliary tool in the differentiation between BoHV1.1, BoHV-1.2 and BoHV-5 isolates.
\end{abstract}

Keywords: BoHV-1.1, BoHV-1.2, BoHV-5, gB, motifs

Recebido para publicação em 5 de julho de 2003

Recebido para publicação, após modificações, em 24 de novembro de 2004

*Autor para correspondência

E-mail: rochama@vet.ufmg.br 


\section{Costa et al.}

\section{INTRODUÇÃO}

O herpesvírus bovino-1 (BoHV-1), causador da rinotraqueíte infecciosa bovina (IBR), tem sido alvo de estudos em várias partes do mundo, devido ao impacto extremamente negativo da infecção por esse vírus na pecuária bovina. A infecção pelo BoHV-1 caracteriza-se por diversas formas clínicas, incluindo doença respiratória, vulvovaginite, balanopostite, encefalite, diminuição nos índices de fecundação e queda brusca na produção de leite. O BoHV-1 é classificado em três subtipos: subtipo 1 (BoHV-1.1), relacionado a infecções no trato respiratório e reprodutivo, subtipo 1.2a (BoHV-1.2a) e subtipo $1.2 \mathrm{~b}$ (BoHV-1.2b), ambos relacionados a infecções no trato reprodutivo (Engels et al.,1981). O herpesvírus bovino-5 (BoHV-5), inicialmente classificado como BoHV-1.3, está relacionado a infecções neurológicas e vem sendo também alvo de diversos estudos (Roizman et al., 1992).

O BoHV-1 e o BoHV-5 pertencem à família Herpesviridae, subfamília Alphaherpesvirinae e apresentam como principal característica um cerne contendo DNA linear de fita dupla e um capsídeo icosadeltahédrico de aproximadamente $100 \mathrm{~nm}$ de diâmetro, contendo 162 capsômeros. O BoHV-1 e o BoHV-5 apresentam um conteúdo de $\mathrm{G}+\mathrm{C}$ de $72 \%$ e seus genomas são formados por um segmento longo único (UL: unique long) e um segmento curto único (US: unique short), flanqueado por dois segmentos repetidos invertidos (Engels et al., 1981). Os genomas desses vírus apresentam $85 \%$ de homologia, o que dificulta sua diferenciação pelas técnicas tradicionais de diagnóstico (Rós e Belák, 1999). Estudos de mapeamento do genoma de alguns isolados de BoHV-1 e BoHV5 , utilizando a restrição enzimática, mostraram ser este um dos melhores métodos para diferenciar isolados. Entretanto, Nadin-Davis e colaboradores (1996) apontam que somente ensaios de restrição enzimática não conseguem correlacionar os tipos genéticos virais e os sinais clínicos apresentados pelos animais infectados.

O gene que codifica a glicoproteína $\mathrm{B}(\mathrm{gB})$ tem se mostrado adequado para o estudo de relações genéticas entre vários tipos de alphaherpesvirus de ruminantes, como os BoHV-1, BoHV-5, herpesvírus cervídeo 1 , herpesvírus caprino $1 \mathrm{e}$ também do herpesvirus simplex humano 1 e 2 . A existência de várias seqüências disponíveis para essa região do vírus favorece o estudo comparativo de novos isolados, inclusive no que concerne ao desenvolvimento de testes sorodiagnóstico específicos (Rós e Belák, 2002)

Este trabalho objetivou diferenciar isolados de herpesvírus bovinos $1.1,1.2$ e 5 , utilizando a região gênica UL27, codificadora da gB.

\section{MATERIAL E MÉTODOS}

A amostra padrão mundial de BoHV-1.1: Colorado/ Cooper (ATTC-VR 864), quinta passagem, e dois isolados de BoHV-5, A663 e EVI-88, ambos na nona passagem, foram utilizados neste estudo. As células MDBK foram cultivadas no meio Mínimo Essencial de Eagle (MEM), suplementado com soro fetal bovino (SFB) inativado e livre do vírus da diarréia bovina. Para a inoculação viral, utilizou-se a monocamada celular com uma confluência de $80 \%$.

A amostra EVI-88, isolada de um surto de meningoencefalite no sul do Brasil, foi caracterizada em 1997 (ROEHE et al., 1997). A amostra A663, isolada na Argentina durante um surto de meningoencefalite em bezerros (Carrillo et al., 1983), foi caracterizada posteriormente (Metzler et al., 1986).

A PCR foi realizada diretamente a partir do sobrenadante do cultivo celular. Foram utilizados os iniciadores desenhados por Nadin-Davis et al. (1996), baseados em parte da seqüência da região única longa (UL27), codificadora da gB, do genoma do BoHV-1 descrita por Whitbeck (1988). O iniciador senso 5'-AAGTGCACACCGTGTTATTTGCG- 3' (posição 241-264) e o iniciador anti-senso 5'-TTGCATTACTTTTGGGGTCAAATGTG-3' (posição 563-588) geram um produto de 308 pb, quando utilizados para amplificar isolados de BoHV-1.1.

As reações foram realizadas segundo NadinDavis et al. (1996) com modificações, em um volume total de $20 \mu \mathrm{l}$, contendo tampão da Taq $10 \mathrm{X}, 10 \mathrm{pmol}$ de cada iniciador, glicerol $1 \%$ 
(v/v), dNTPs $200 \mu \mathrm{M}, \quad 1 \mathrm{U}$ de Taq DNA polimerase, $2 \mu \mathrm{l}$ de sobrenadante de cultivo

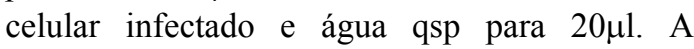
concentração de $\mathrm{MgCl}_{2}$ foi testada variando entre 1,5 e $2,5 \mathrm{mM}$, sendo escolhida a concentração de $1,5 \mathrm{mM}$. Cada reação de $20 \mu \mathrm{l}$ foi dividida em duas partes: a primeira (MIX 1) contendo o tampão $10 \mathrm{X}, \mathrm{MgCl}_{2}$, glicerol, cada iniciador, $2 \mu \mathrm{l}$ da amostra e água qsp para $16 \mu \mathrm{l}$, e a segunda (MIX 2) contendo a taq DNA polimerase, dNTPs e água qsp para $4 \mu \mathrm{l}$, que foi adicionada ao tubo, atravessando o óleo mineral após uma etapa inicial a $98^{\circ} \mathrm{C}$ por seis minutos. $\mathrm{O}$ programa utilizado consistiu de cinco ciclos de $95^{\circ} \mathrm{C}$ por um minuto, cinco ciclos de $55^{\circ} \mathrm{C}$ durante um minuto, $72^{\circ} \mathrm{C}$ por um minuto, seguido de 35 ciclos de $95^{\circ} \mathrm{C}$ por um minuto, $60^{\circ} \mathrm{C}$ por um minuto, $72^{\circ} \mathrm{C}$ por dois minutos, e uma etapa final de extensão de seis minutos a $72^{\circ} \mathrm{C}$. Dez microlitros de cada reação de PCR foram submetidos à eletroforese $(120 \mathrm{~V}$ por 1 hora) em géis de poliacrilamida $6 \%$, corridos em tampão TBE $(89 \mathrm{mM}$ Tris-Borato, $2 \mathrm{mM}$ EDTA, pH8,2) e corados pela prata segundo Dias Neto (1996). Para determinação do tamanho dos produtos de PCR foram incluídos em cada corrida um marcador de tamanho molecular, sendo utilizados o $\mathrm{pGEM}^{1}$, com fragmentos variando entre 36 a 2645 pares de base (Rocha et al., 1999). O gel foi fotografado com o auxílio do equipamento Image Master $^{\mathrm{TM}}$ $\operatorname{VDS}^{2}$.

Os produtos dos isolados A663 e EVI-88 foram novamente amplificados em um volume de $50 \mu \mathrm{l}$. A banda desejada foi visualizada mediante a incidência de luz ultravioleta $(320 \mathrm{~nm})$ em gel de agarose $1 \%$ corado por brometo de etídio, retirada do gel com o auxílio de bisturi e colocada em tubo de $1,5 \mathrm{ml}$ para purificação. A banda retirada foi cortada sucessivamente, seguida do congelamento a $70^{\circ} \mathrm{C}$ durante 10

\footnotetext{
${ }^{1}$ Promega, EUA.

${ }^{2}$ Amersham Pharmacia Biotech, Suécia.
}

minutos e centrifugação a 15.000rpm durante cinco minutos. O sobrenadante foi colocado em um tubo de $1,5 \mathrm{ml}$ novo e estéril, e estocado até o uso a $4^{\circ} \mathrm{C}$. Os produtos de PCR purificados foram seqüenciados pela Bioagro - Universidade Federal de Viçosa, obtendo-se pelo menos três seqüências para cada isolado, as quais foram analisadas utilizando os programas BLASTN, BLASTN gapped e BLASTX, disponíveis no endereço eletrônico do National Center for Biotechnology Information $(\mathrm{NCBI})^{3}$, e depositadas no GenBank (NCBI) ${ }^{3}$.

As seqüências de BoHV-5 editadas foram alinhadas com três seqüências de BoHV-1.2 (Nos. de acesso U14106, U14105 e U14107) e uma de BoHV-1.1 (Z78205), previamente depositadas no GenBank (NCBI) $)^{3}$ O alinhamento foi feito com o auxílio do programa ClustalW ${ }^{4}$.

\section{RESULTADOS E DISCUSSÃO}

Ao analisar os amplicons em géis de poliacrilamida $6 \%$ corados pela prata, observouse que o isolado de BoHV-1.1 (Colorado) gerou um produto de PCR de $308 \mathrm{pb}$ e os isolados de BoHV-5 (A663 e EVI-88) geraram um produto de PCR de 352 pb (Fig. 1). Nessa primeira análise, verifica-se que os herpesvírus bovinos tipos 1 e 5 apresentaram diferenças nessa região gênica, resultado já observado para amostras de BoHV-1.1 e BoHV-1.2 por Nadin-Davis et al. (1996).

Após a edição, as seqüências dos isolados de BoHV-5 (A663 e EVI-88) foram depositadas no GenBank. A seqüência da A663 recebeu o número de acesso AY185365 e amostra EVI-88 ainda não se encontra disponível. As seqüências de BoHV-5 apresentaram 100\% de similaridade entre si, o que pode ser observado na Fig. 2. 


\section{Costa et al.}

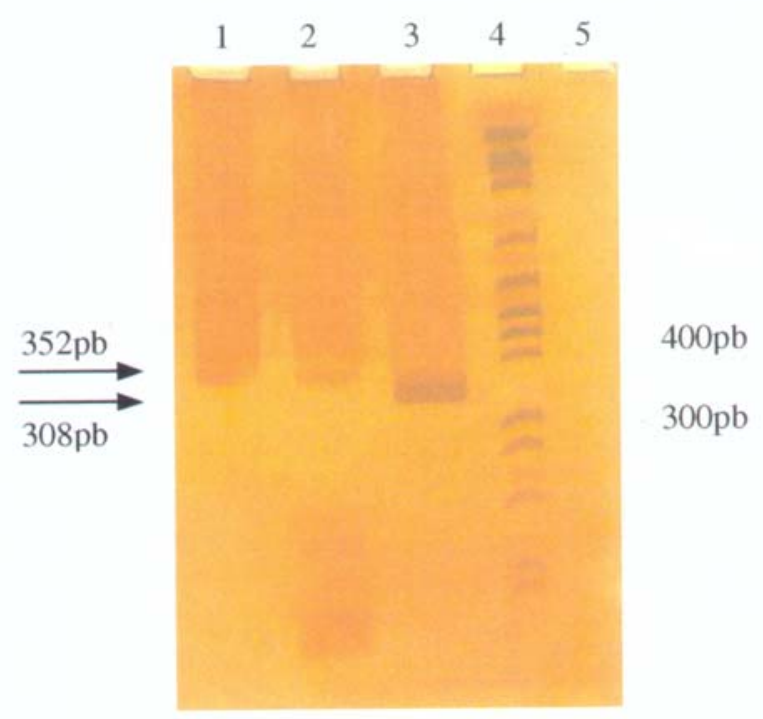

Figura 1. Análise dos produtos de PCR (seqüência parcial da região UL27, que codifica para a gB) em gel de poliacrilamida 6\%, corado pela prata. Canaleta 1 - EVI-88 (BoHV-5), canaleta 2 - A663 (BoHV-5), canaleta 3 - Colorado (BoHV-1.1), canaleta 4 - padrão de tamanho molecular (pGEM), canaleta 5 controle negativo (master mix)

Ao analisar a seqüência dos fragmentos amplificados das amostras de BoHV-5 (A663 e EVI-88), foram encontradas duas seqüênciasmotivo, presentes em maior quantidade: 5'-G(A/T)CC- 3' e 5'-TTCCC(C/-) GCC(C/-) (Fig. 2). Seqüências-motivo (motifs) são seqüências curtas, de aproximadamente 4 a 20pb, que se encontram repetidas ao longo do genoma, de forma difusa, ou seja, espalhadas aleatoriamente ou enfileiradas uma após a outra, ou em série (in tandem) (Umene et al., 1991). Nadin-Davis et al. (1996) também verificaram a presença dessas duas seqüências-motivo ao analisarem a mesma região em seqüências de BoHV-1.1 e BoHV-1.2. Todos os isolados de BoHV-1.1 estudados por esses pesquisadores apresentaram seqüências idênticas entre si. De maneira interessante, esse comportamento não foi verificado nos isolados de BoHV-1.2, os quais apresentaram diferenças entre suas seqüências, principalmente no tocante ao tamanho molecular. Os isolados de BoHV-1.2: (K22, F1 e M) geraram produtos de $348 \mathrm{pb}, 338$ $\mathrm{pb}$ e $337 \mathrm{pb}$, respectivamente. As seqüências de BoHV-5 geradas no presente trabalho em comparação com as seqüências de BoHV-1.1 e BoHV-1.2 utilizadas no alinhamento (Fig. 2) mostraram maior número de seqüências-motivo. Provavelmente, em razão do maior número de repetições, os produtos de PCR obtidos dos isolados EVI-88 e A663 apresentaram maior tamanho molecular, podendo ser visualmente diferenciados no gel de poliacrilamida (Fig. 1).

Verificou-se a ocorrência de uma seqüênciamotivo maior, denominada de grande-motivo, composta pelas seqüências curtas encontradas anteriormente, orientados da seguinte maneira: GACC-GTCC- TTCCCCGCCC -GACC. Essa orientação ou grande-motivo está localizada entre os nucleotídeos de número 465 ao 518 (número de acesso no GenBank: U14106) e varia no seu tamanho de acordo com a variação no número de cópias de GTCC localizados em série. As repetições de GTCC no grande-motivo para as seqüências de BoHV-5 (A663 e EVI-88) foram em número de cinco. A seqüência do BoHV-1.1 (Colorado) apresentou uma única repetição de GTCC e as seqüências de BoHV-1.2 (K22 e M1) apresentaram quatro repetições, em contraste com a seqüência do isolado $\mathrm{F} 1$, que apresentou somente uma repetição de GTCC. As seqüências dos isolados de BoHV-5 apresentaram o maior número de repetições de GTCC em série no grande-motivo quando comparadas com os isolados de BoHV-1.2 e BoHV-1.1 (Fig. 2). 
Utilização de parte da região codificadora da glicoproteína b...

\begin{abstract}
EVI-88 AAGTGCACACCGTGTTATTTGCGGCTGTTTGTTTTTCCTGGAGGCGGGACGTGCGCGCG
Figura 2. Alinhamento da seqüência parcial do gene (UL27) que codifica para a gB. As seqüências das amostras de BoHV-5 (A663 e EVI-88) foram efetuadas durante este trabalho, tendo sido a seqüência da amostra A663 depositada no GenBank sob o número de acesso AY185365. As demais amostras encontravam previamente depositadas por outros autores e são: BoHV-1.2 - U14106 (K22), U14107 (M) e U14105 (F1) e do BoHV-1.1: Z78205 (Colorado). Visualização das seqüências-motivo presentes dentro do grande motivo (em vermelho) e das seqüências-motivo $\mathrm{C}(\mathrm{G} / \mathrm{T}) \mathrm{CC}$ e TTCCC(C)GCC(C) que estão localizadas de forma aleatória, fora do grande-motivo (em azul e em verde, respectivamente).
\end{abstract}




\section{Costa et al.}

Foi possível diferenciar os isolados de BoHV-1.2 em subtipos a, b, pois a seqüência de K22 teve comportamento diferente da seqüência de F1. Com a metodologia utilizada, este resultado é semelhante aos de Miller et al. (1984) e Miller et al. (1991) que classificaram o isolado K22 como BoHV-1.2b e o isolado F1 como BoHV-1.2a, ao utilizarem ensaios de restrição enzimática. As seqüências dos isolados K22 e M apresentaram cinco repetições em série da seqüência-motivo CGCC dentro do grande-motivo. A seqüência do isolado F1 apresentou apenas uma repetição, estando mais próxima, neste ponto, das seqüências dos isolados de BoHV-1.1 (Fig. 2). A seqüência do isolado F1 apresentou maior número de seqüências-motivo contidas aleatoriamente fora do grande-motivo do que as seqüências dos isolados de BoHV-1.1., assemelhando-se neste ponto com as seqüências dos isolados de BoHV-1.2. Essa semelhança que a seqüência do isolado F1 apresenta com as seqüências dos isolados de BoHV-1.1 também pode ser verificada em relação aos sintomas clínicos descritos por vários autores. Somente os isolados de BoHV-1.1 e BoHV-1.2a são considerados causadores de abortos, sendo diferentes dos isolados de BoHV-1.2b que não causam aborto (Miller et al.,1988; Miller et al.,1991; Engels et al.,1981). Além da seqüência curta GTCC dentro das repetições em grande motivos já discutidas, foi possível, ainda, a diferenciação entre os isolados de BoHV-1.1, BoHV-1.2 e BoHV-5, juntamente com a comparação das variações do número de cópias das seqüências-motivo contidas aleatoriamente no genoma que codifica a $\mathrm{gB}$. $\mathrm{O}$ isolado $\mathrm{M}$ foi classificado como BoHV-1.2 (Nadin-Davis et al., 1996), mas os autores não subclassificaram a amostra em 1.2a ou 1.2b. O fato de o isolado M ter se comportado de maneira similar ao isolado K22 (BoHV-1.2b) no que se refere ao estudo das seqüências-motivo, sugere que esse isolado possa ter o mesmo subtipo desse. Neste trabalho, as amostras de BoHV-5: A663 e EVI-88 comportaram-se de maneira idêntica na análise das seqüências-motivo. Como relatado por Carrillo et al. (1983) e Roehe et al. (1997) para as amostras A663 e EVI-88, respectivamente, elas foram isoladas durante surtos de meningoencefalite. A análise das seqüências de DNA demonstrou que as seqüências-motivo contidas em parte do gene que codifica a gB são uma ferramenta promissora para a diferenciação entre isolados de BoHV-1.1, BoHV-1.2 e BoHV-5.

\section{AGRADECIMENTOS}

Este trabalho foi financiado pela Fundação de Amparo à Pesquisa do Estado de Minas Gerais.

\section{REFERÊNCIAS BIBLIOGRÁFICAS}

CARRILLO, B.J.; POSPISCHIL, A.; DAHME, E. Pathology of a bovine viral necrotizing encephalitis in Argentina. Zbl. Vet. Med. B., v.30, p.161-168, 1983.

CLUSTAL W (online). Available from world wide web. Disponível em: <http://clustalw. genome.ad.jp>.

DIAS NETO, E.; RAHAL, P.; CABALLERO, O.L.S.D. et al. DNA ligation quality control by competitive PCR. Trends Genet., v.12, p.341342, 1996.

ENGELS, M.; STECK, F.; WYLER, R. Comparison of the genomes of infectious bovine rhinotracheitis and infectious pustular vulvovaginitis virus strain by restriction endonuclease analysis. Arch. Virol., v.67, p.169174, 1981.

METZLER, A.E.; SCHUDEL, A.A.; ENGELS, M. Bovine herpesvirus 1: molecular and antigenic characteristics of variant viruses isolated from calves with neurological disease. Arch. Virol., v.87, p.205-217, 1986.

MILLER, J.M.; VAN DER MAATEN, M.J. Reproductive tract lesions in heifers after intrauterine inoculation with infectious bovine rhinotracheitis virus. Am. J. Vet. Res., v.45, p.790-794, 1984.

MILLER, J.M.; VAN DER MAATEN, M.J.; WHETSTONE, C.A. Abortifacient property of bovine herpesvirus type 1 isolates that represent three subtypes determined by restriction endonuclease analysis of viral DNA. Am. J. Vet. Res., v.52, p.458-461, 1991.

MILLER, J.M.; VAN DER MAATEN, M.J.; WHETSTONE, C.A. Effects of a bovine herpesvirus-1 isolate on reproductive function in heifers: Classification as a type-2 (infectious pustular vulvovaginitis) virus by restriction 
Utilização de parte da região codificadora da glicoproteína b...

endonuclease analysis of viral DNA. Am. J. Vet. Res., v.49, p.1653-1656, 1988.

NADIN-DAVIS, S.A.; LUTZE-WALLACE, C.; ZHONG, X. Bovine herpesvirus 1 isolates contain variable copy numbers of GC-rich tandem repeats in the gI non-coding regions of their genomes. Virus Gene, v.13, p.263- 268, 1996.

ROCHA, M.A.; BARBOSA, E.F.; GUEDES, R.M.C. et al. Detection of BHV-1 in a naturally infected bovine fetus by a nested PCR assay. Vet. Res. Communic., n.23, p.133-141, 1999.

ROEHE, P.M.; SILVA, T.C.; NARDI, N.B. et al. Diferenciação entre os vírus da rinotraqueíte infecciosa bovina (BHV-1) e herpesvirus da encefalite bovina (BHV-5) com anticorpos monoclonais. Pesq. Vet. Bras., v.17, p.41-44, 1997.

ROIZMAN, B.; DESROSIERS, R.C.; FLECKENSTEIN, B. et al. The family Herpesviridae: an update. Virology Division News. Arch. Virol., v.123, p.425-449, 1992.
RÓS, C.; BELÁK, S. Characterization of glycoprotein B gene from ruminant alphaherpesviruses. Virus Gene, v.24, p.99-105, 2002.

RÓS, C.; BELÁK, S. Studies of genetic relationships between bovine, caprine, cervine and rangiferine alphaherpesviruses and improved molecular methods for virus detection and identification. J. Clin. Microbiol., v.37, p.12471253, 1999.

SAMBROOK, J.; FRITSCH, E.F.; MANIATIS, T. Molecular cloning, a laboratory manual. 2.ed. Cold Spring Harbor: Cold Spring Harbor Laboratory, 1989.

UMENE, K. Recombination of the internal direct repeat element DR2 responsable for the fluidity of the $a$ sequence of Herpes Simplex virus type 1. J. Virol., v.65, p.5.410-5.416, 1991.

WHITBECK, J.C.; BELLO, L.J.; LAWRENCE, W.C. Comparison of the bovine herpesvirus $1 \mathrm{gI}$ gene and herpes simplex virus type $1 \mathrm{gB}$ gene. $J$. Virol., v.62, p.3319-3327, 1988. 